\title{
POTENCIAL DE APLICAÇÃO DE BIOSURFACTANTE BACTERIANO DO TIPO LIPOPEPTÍDEO NA BIORREMEDIAÇÃO DE AMBIENTES CONTAMINADOS
}

\author{
J. A. M. $\operatorname{LEMOS}^{1}$, I. W. L. FRANÇA ${ }^{1}$, B. N. SANTOS ${ }^{1}$, V. M. M. MELO ${ }^{2}$ e L. R. B. \\ GONÇALVES ${ }^{1}$ \\ ${ }^{1}$ Universidade Federal do Ceará, Departamento de Engenharia Química \\ ${ }^{2}$ Universidade Federal do Ceará, Departamento de Biologia \\ E-mail para contato: 1rg@ufc.br
}

\begin{abstract}
RESUMO - Biossurfactantes são moléculas constituídas de regiões apolares e polares, característica que lhes dá a capacidade de interagir com fluidos de diferentes polaridades. Tal propriedade lhes garante vasta aplicação como emulsificante, detergente e dispersante. Apresentam vantagens em relação aos surfactantes sintéticos como maior eficiência, baixa toxicidade e biodegradabilidade. A utilização de biossurfactantes em biorremediação necessita da avaliação do nível de toxicidade e eficácia destas moléculas em remover poluentes, como hidrocarbonetos. Este trabalho visa analisar a toxicidade de um biossurfactante bacteriano, além da sua capacidade em remover hidrocarbonetos de solos contaminados e comparar sua eficiência frente à surfactantes sintéticos. Resultados mostraram a baixa toxicidade do biossurfactante em sementes de alface e micro crustáceo, bem como a remoção de $91 \%$ de petróleo em areia contaminada, valor superior aos observados pelos surfactantes sintéticos analisados (SDS e Triton).
\end{abstract}

\section{INTRODUÇÃO}

Surfactantes são compostos químicos que possuem ação tensoativa. Suas moléculas são compostas por porções hidrofílicas e hidrofóbicas, as quais se distribuem na interface de fases fluidas com diferentes polaridades. Surfactantes têm vasta aplicação industrial, contando como uma de suas maiores utilizações em processos relacionados a desastres ambientes, por serem capazes de dispersar, por exemplo, óleo derramado em águas oceânicas (Pacwa-Płociniczak et al. 2011).

A utilização desses dispersantes (surfactantes sintéticos) proporciona o benefício de reduzir os impactos causados pelos compostos poluentes, porém acarretam uma série de outros problemas ambientais, principalmente devido à sua toxicidade e baixa biodegradabilidade (Rufino et al. 2013). Os biossurfactantes são moléculas de ação similar, resultado do metabolismo de microrganismos, tais como bactérias, leveduras e fungos. Os biossurfactantes se contrapõem aos surfactantes quimicamente sintetizados por apresentarem diversas vantagens em relação a estes: aceitabilidade ambiental, baixa toxicidade, biodegradabilidade em ambientes terrestres e aquáticos, entre outros (Al-Wahaibi et al. 2013).

Dentro deste contexto, o objetivo deste trabalho visa avaliar o potencial de aplicação de biossurfactante bacteriano do tipo lipopeptídeo produzido pela cepa ICA56 (isolada de manguezal cearense) em ambientes contaminados com hidrocarbonetos, bem como caracterizar suas propriedades toxicológicas, tendo em vista sua aplicabilidade ambiental. 


\section{METODOLOGIA}

\subsection{Micro-organismo e meio de estoque}

A cepa ICA56 foi previamente isolada de manguezal no município de Icapuí (Barra Grande) no estado do Ceará. Este micro-organismo foi apresentado como potencial produtor de biossurfactante por Lima (2013), por intermédio da identificação do gene sfp, responsável pela produção de surfactina, através de técnica de PCR (Reação em Cadeia da Polimerase). Esta linhagem pertence à coleção de bactérias do Laboratório de Ecologia Microbiana e Biotecnologia (LEMBIOTECH) do Departamento de Biologia da Universidade Federal do Ceará e foi gentilmente cedido para a realização do presente estudo. A linhagem foi mantida em meio APGE (ágar/peptona/glicose/extrato de levedura) e repicada a cada 30 dias.

\subsection{Produção e obtenção do biossurfactante bruto}

A cepa ICA56 foi cultivada em meio mineral (BARRETO, 2011) contendo glicose $\left(10,0\right.$ g.. $\left.{ }^{-1}\right)$ como fonte de carbono e sulfato de amônio $\left(1,0\right.$ g. $\left.\mathrm{L}^{-1}\right)$ como fonte de nitrogênio. Para a realização dos ensaios, adicionou-se (10\% de inóculo) ao meio de cultivo, para um volume final de fermentação de $100 \mathrm{~mL}$. O ensaio foi realizado em agitador orbital a $30^{\circ} \mathrm{C}$ e $180 \mathrm{rpm}$, durante 48 horas. Após o período de cultivo, a biomassa foi removida por centrifugação a $10000 \mathrm{~g}$, a $4^{\circ} \mathrm{C}$ por 15 minutos e o sobrenadante foi acidificado para $\mathrm{pH} 2,0 \mathrm{com} \mathrm{HCl} 3 \mathrm{M}$. A solução resultante permaneceu em repouso por aproximadamente 24 horas $\left(4^{\circ} \mathrm{C}\right)$ para que ocorresse a precipitação do biossurfactante. $\mathrm{O}$ extrato rico em biossurfactante foi centrifugado $\left(10000 \mathrm{~g}, \mathrm{a} 4^{\circ} \mathrm{C}\right.$ por 15 minutos) e o precipitado obtido foi conduzido para estufa de secagem $\left(50{ }^{\circ} \mathrm{C}\right.$, por 24 horas), fornecendo assim o biossurfactante bruto (Pereira et al. 2013).

\subsection{Remoção de hidrocarbonetos}

Avaliou-se a capacidade de remoção de hidrocarbonetos do biossurfactante produzido pela cepa ICA56 frente a dois contaminantes: petróleo bruto (amostra da Bacia de Campos, cedida pelo Grupo de Pesquisa em Termofluidodinâmica Aplicada (GPTA) do Departamento de Engenharia Química da Universidade Federal do Ceará) e óleo de motor SAE 15W-40. Segundo a metodologia descrita por Aparna et al. (2012), amostras de $20 \mathrm{~g}$ de areia (50/70 mesh) foram contaminadas com $2 \mathrm{~g}$ do hidrocarboneto e então submetidas a tratamento com solução do biossurfactante (caldo de cultivo ou biossurfactante bruto, utilizando água como controle). A areia contaminada foi mantida em agitador orbital a $150 \mathrm{rpm}$ e $27^{\circ} \mathrm{C}$, por 24 horas. Após este período, as amostras foram centrifugadas para separação da solução de lavagem e da areia. A quantidade de hidrocarboneto removida da areia foi determinada gravimetricamente (extração com hexano). Surfactantes químicos (SDS e Triton) foram utilizados para análise comparativa de eficiência em relação ao biossurfactante produzido no presente estudo, em termos de remoção de hidrocarbonetos em solo contaminado. Tanto os surfactantes sintéticos, como o biossurfactante foram padronizados na concentração de $250 \mathrm{mg} \cdot \mathrm{L}^{-1}$, com finalidade de comparação.

\subsection{Ensaios de toxicidade}

Germinação de sementes de alface (Lactuca sativa): Foram utilizados papeis-filtro inseridos em placas de Petri, onde o papel foi umedecido com solução de biossurfactante a diferentes concentrações e então adicionadas 10 sementes de alface. Após 5 dias de incubação à $24{ }^{\circ} \mathrm{C}$, foram verificadas as sementes que sofreram germinação e o tamanho de suas raízes. O Índice e Germinação (IG), conforme apresentado por Souza et al. (2013), faz relação entre os parâmetros anteriores e 
representa um dos indicativos da toxicidade de determinada substância. Sua rotina de cálculos está apresentada a seguir:

$$
\begin{aligned}
& \% G S=\left(\frac{\% G E}{\% G C}\right) * 100 \\
& \% C R=\left(\frac{M C E}{M C C}\right) * 100 \\
& \% I G=\frac{(\% G S)(\% C R)}{100}
\end{aligned}
$$

Onde:

$\mathrm{MCE}=$ Crescimento no extrato (média), em mm;

$\mathrm{MCC}=$ Crescimento no controle (média), em mm;

$\% \mathrm{GE}=$ Porcentagem de germinação no extrato (média), adimensional;

$\%$ GC = Porcentagem de germinação no controle (média), adimensional;

$\% \mathrm{IG}=$ Índice de germinação (média), adimensional.

Sobrevivência de microcrustáceo: cistos comerciais de Artemia salina foram eclodidos em solução salina $(3 \% \mathrm{~m} / \mathrm{v})$. Aproximadamente 10 larvas do microcrustáceo foram condicionadas em tubos de ensaio e mantidas em soluções a diferentes concentrações do biossurfactante. Após período de 24 horas sob iluminação e temperatura de $25^{\circ} \mathrm{C}$ constantes, foi realizada a contagem do número de larvas sobreviventes. Estes dados permitem o cálculo da $\mathrm{CL}_{50}$, que representa a concentração da substância capaz de apresentar letalidade para metade da população de Artemia salina. Tal índice representa um fator para caracterização da biotoxicidade do composto produzido (Souza et al. 2013). Soluções de biossurfactante bruto a concentrações de $0,12,5,25,50,100,200,350,500$ e 750 mg.L. ${ }^{-1}$ foram utilizadas neste estudo.

\section{RESULTADOS E DISCUSSÃO}

\subsection{Remoção de hidrocarbonetos}

Os biossurfactantes são apresentados como biomoléculas promissoras em contaminações ambientais por hidrocarbonetos, por serem relatados como biodegradáveis e de baixa toxicidade (Aparna et al., 2012). O potencial de remoção de hidrocarbonetos foi avaliado em óleo de motor e petróleo bruto, com a utilização do caldo resultante do cultivo da cepa ICA56, bem como de solução bruta do biossurfactante, além de água destilada como controle. Em termos de finalidade comparativa, dois surfactantes sintéticos (SDS e Triton) também foram utilizados neste estudo. A Tabela 1 apresenta a quantidade percentual de hidrocarbonetos removidos da areia contaminada, após remoção com as soluções mencionadas acima. 
Tabela 1 - Potencial de remoção de hidrocarbonetos da areia contaminada

\begin{tabular}{c|c|c}
\hline Tratamento & Petróleo removido $(\boldsymbol{\%})$ & Óleo de motor removido $(\boldsymbol{\%})$ \\
\hline Caldo de cultivo & $85,00 \pm 2,06$ & $90,80 \pm 0,60$ \\
Biossurfactante bruto & $76,89 \pm 3,20$ & $88,60 \pm 0,90$ \\
Água destilada & $36,10 \pm 1,10$ & $33,12 \pm 2,80$ \\
SDS & $81,20 \pm 0,50$ & $79,20 \pm 1,30$ \\
Triton X-100 & $76,10 \pm 2,10$ & $70,40 \pm 0,40$ \\
\hline
\end{tabular}

A Tabela 1 apresenta que as soluções que continham a molécula de biossurfactante foram mais eficientes na remoção dos hidrocarbonetos, quando comparados aos surfactantes sintéticos. Os percentuais de remoção apresentados pelos surfactantes químicos SDS e Triton X-100 foram menores que o apresentado pelo biossurfactante tanto em petróleo como óleo de motor, o que ressalta uma maior eficiência dos biossurfactantes em comparação aos surfactantes sintéticos.

O tratamento com caldo de cultivo foi o que apresentou maiores percentuais de remoção de petróleo e óleo de motor, com valores de $85 \%$ e $90,8 \%$ respectivamente. A remoção realizada por solução de biossurfactante bruto apresentou valores de remoção levemente menores quando comparado ao caldo. Tal fato pode ser explicado pela perda de material do biossurfactante, durante as operações de tratamento do caldo para semi-purificação do biossurfactante. Mesmo com a diferença mostrada na Tabela 1, os valores são bastante similares, o que mostra o potencial do biossurfactante produzido em aplicações de biorremediação. Tal resultado se mostra interessante, pois o caldo do cultivo poderia ser diretamente aplicado no tratamento do solo contaminado, reduzindo custos de produção do biossurfactante pela não utilização de processos unitários de purificação.

Joshi et al. (2008) obtiveram remoção de 30\% de óleo da areia contaminada com petróleo ao tratarem a mesma com biossurfactante produzido por cepa de Bacillus sp. Lai et al. (2009) encontraram resultados similares ao presente estudo, onde observaram maior eficiência de biossurfactante em comparação a surfactantes químicos (Tween 80 e Triton X-100). Jain et al. (2009) ao estudarem a eficiência de remoção de petróleo de areia contaminada por surfactantes observaram o seguinte resultado: surfactina (68\%), Tween 80 (52\%), SDBS (51\%). Tais resultados revelam que os biossurfactantes foram mais eficientes que os surfactantes sintéticos na remoção de hidrocarbonetos.

\subsection{Ensaios de toxicidade}

Primeiramente foram realizados os testes de germinação de sementes de Lactuca sativa (alface) para a caracterização da biotoxicidade do biossurfactante produzido. Vale ressaltar que poucos estudos têm sido realizados com a finalidade de verificar a toxicidade destes bioprodutos tendo em vista aplicações ambientais (Souza Sobrinho et al. 2013). A Figura 1 apresenta a correlação entre o índice de germinação (IG) em diferentes concentrações do biossurfactante. 
total de organismos). A Figura 2 apresenta a taxa de mortalidade do microcrustáceo para cada concentração testada e a Equação 4 representa o modelo matemático encontrado como ajuste dos dados experimentais $\left(\mathrm{R}^{2}=0,984\right)$.

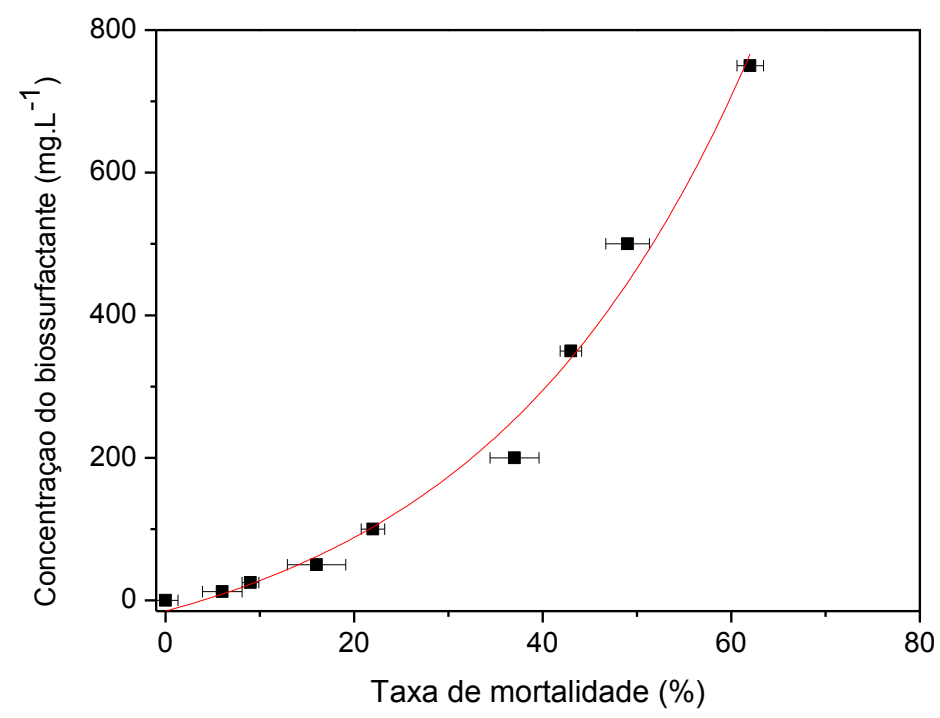

Figura 2 - Taxa de mortalidade do microcrustáceo Artemia salina em diferentes concentrações do biossurfactante produzido no cultivo da cepa ICA56 (ajuste exponencial dos dados).

$y=103,24 \cdot e^{\frac{x}{28,86}}-118,21$

Dolabella (1997) elaborou uma classificação quanto à toxicidade das espécies químicas em microcrustáceos. Segundo o autor, $\mathrm{CL}_{50}$ menor que $80 \mathrm{mg} . \mathrm{L}^{-1}$ é altamente tóxico, $\mathrm{CL}_{50}$ entre 80 e 250 mg. $\mathrm{L}^{-1}$ é moderadamente tóxico e $\mathrm{CL}_{50}$ maior que $250 \mathrm{mg} . \mathrm{L}^{-1}$ a substância pode ser dita atóxica. A partir do modelo, ajustado para os dados de taxa de mortalidade dos microcrustáceos e dose de biossurfactante, obtém-se a $\mathrm{CL}_{50}$ do biossurfactante produzido como sendo de aproximadamente 465,6 mg.L ${ }^{-1}$. Segundo a classificação de Dolabella (1997) o biossurfactante produzido pela cepa ICA56 não apresentou efeitos tóxicos ao organismo estudado, o que pode viabilizar sua aplicação em ecossistemas marinhos.

Pode-se verificar a partir da Figura 2, que concentrações iguais ou inferiores a $100 \mathrm{mg} . \mathrm{L}^{-1}$ apresentam valores de mortalidade muito baixos. Felix (2012) observou um valor de $\mathrm{CL}_{50}$ igual a $612,57 \mathrm{mg} . \mathrm{L}^{-1}$ ao estudar a surfactina produzida por Bacillus subtilis. Silva et al. (2013) estudaram biossurfactante produzido por substratos de baixo custo e obtiveram resultados similares, onde o composto produzido não apresentou efeitos significativos de toxicidade sobre Artemia salina. Estudando a toxicidade de surfactantes químicos, Liwarska-Bizukojc et al. (2005) observaram que surfactantes aniônicos (SDS, APE) e não iônicos (AE, AES) são extremamente tóxicos, apresentando $\mathrm{CL}_{50}$ variando de valores menores que $10 \mathrm{mg} . \mathrm{L}^{-1}$ a valores próximos de $100 \mathrm{mg} . \mathrm{L}^{-1}$.

Li (2008) observou que surfactantes sintéticos como SDS e Triton X-100 apresentaram $\mathrm{CL}_{50}$ de 0,36 e $11,18 \mathrm{mg} . \mathrm{L}^{-1}$, respectivamente, sendo valores muito menores que o encontrado no presente estudo. Tais resultados evidenciam que a utilização de surfactantes químicos pode ser extremamente nociva aos ambientes onde são aplicados e que os biossurfactantes são extremamente viáveis, pelos seus baixos níveis de toxicidade. 


\title{
4. CONCLUSÃO
}

A utilização de biossurfactantes se mostra uma alternativa extremamente viável em casos de tratamento ambiental, como remediação de solos e ambientes aquáticos, pois estes compostos têm maior potencial de remoção de contaminantes, bem como apresentam níveis de toxicidade menores que os surfactantes químicos disponíveis no mercado. $\mathrm{O}$ biossurfactante tipo lipopeptídeo produzido por ICA56 apresentou potencial de remoção de hidrocarbonetos de areia contaminada superiores a $80 \%$, possuindo valores de toxicidade baixos. O índice de germinação para este composto foi também superior a $80 \%$ e seu $\mathrm{CL}_{50}$ o classifica como composto atóxico, apesentando indícios de sua aplicabilidade e aceitabilidade ambiental.

\section{REFERÊNCIAS BIBLIOGRÁFICAS}

\begin{abstract}
AL-WAHAIBI ,Y.; SANKET, J.; AL-BAHRY, S.; ELSHAFIE, A.; AL-BEMANI, A.; SHIBULAL B. Biosurfactant production by Bacillus subtilis B30 and its application in enhancing oil recovery, Colloids and Surfaces B: Biointerfaces, v. 114, p. 324-333, 2013.
\end{abstract}

APARNA, A; SRINIKETHAN, G.; SMITHA, H. Production and characterization of biosurfactant produced by a novel Pseudomonas sp. 2B, Coll. and Surf. B, vol. 95, p. 23-29, 2012.

BARRETO, R. V. G. Prospecção de micro-organismos e genes envolvidos com a produção de biossurfactantes em solos de manguezais, 2011. Tese (Doutorado em Doutorado em Biotecnologia) Rede Nordeste de Biotecnologia (RENORBIO) Universidade Federal do Ceará, 2011.

DOLABELLA, M. F. Triagem in vitro para atividade antitumoral e anti Trypanossoma cruzi de extratos vegetais, produtos naturais e substâncias sintéticas. Dissertação (Mestrado em Farmacologia) - Departamento de Fisiologia e Farmacologia, Universidade Federal de Minas Gerais, Belo Horizonte, 1997.

FELIX, A. K. Caracterização e estudo da aplicabilidade do biossurfactante produzido por Bacillus subtilis LAMI005 a partir de suco de caju. 2012. Dissertação (Mestrado em Engenharia Química), Departamento de Engenharia Química, Universidade Federal do Ceará (UFC), Fortaleza - Ceará, 2012.

JAIN, R. M.; MODY, K.; MISHRA, A.; JHA, B. Physicochemical characterization of biosurfactant and its potential to remove oil from soil and cotton cloth, Carbohydrate

JOSHI, S.; BHARUCHA, C.; JHA, S.; YADAV, S.; NERURKAR, A;. A. J. DESAI. Biosurfactant production using molasses and whey under thermophilic conditions, Biores. Tech. vol. 99, p. 195199, 2008.

LI, M. Effects of nonionic and ionic surfactants on survival, oxidative stress, and cholinesterase activity of planarian. Chemosphere, v. 70 (10), p. 1793-1806, 2008. 
LIMA, L. B. Frequência de bactérias produtoras de biossurfactantes lipopeptídeos em sedimentos de manguezais do Ceará, 2002. Dissertação (Mestrado em Ciências Marinhas Tropicais) - Intituto Ciências do Mar, Universidade Federal do Ceará, Fortaleza, 2002.

LIWARSKA-BIZUKOJC, E.; MIKSCH, K.; MALACHOWSKA-JUTSZ, A.; KALKA, J. Acute toxicity and genotoxicity of five selected anionic and nonionic surfactants. Chemosphere, v. 58, p. 1249-1253, 2005.

LUNA, J. M. ; RUFINO, R. D. ; SARUBBO, L. A. ; CAMPOS-TAKAKI, G. M. . Characterisation, surface properties and biological activity of a biosurfactant produced from industrial waste by Candida sphaerica UCP0995 for application in the petroleum industry. Coll. and Surf. B, Biointerfaces, v. 102, p. 202-209, 2013.

MILliOLI, V. S.; SERVULO, E. L. C.; SOBRAL, L. G. S.; CARVALHO, D. D. Bioremediation of crude oil-bearing soil: evaluating the effect of Rhamnolipid addition to soil toxicity and to crude oil biodegradation efficiency, Glob. NEST J. v. 11 (2), 181-188, 2009.

PACWA-PŁOCINICZAK, M.; PŁAZA, G. A.; PIOTROWSKA-SEGET, Z.; CAMEOTRA, S. S. Environmental Applications of Biosurfactants: Recent Advances. Int. J. Mol. Sci, v. 12, p. 633-654, 2011.

PEREIRA, J. F. B.; GUDIÑA, E. J.; COSTA, R.; VITORINO, R.; TEIXEIRA, J. A.; COUTINHO, J. A. P.; RODRIGUES, L. R.; Optimization and characterization of biosurfactant production by Bacillus subtilis isolates towards microbial enhanced oil recovery applications, Fuel, v. 111, p. 259-268, 2013.

RUFINO, R. D.; LUNA, J. M.; MARINHO, P.H.C.; FARIAS, C. B. B.; FERREIRA, S. R. M. ; SARUBBO, L. A. Removal of petroleum derivative adsorbed to soil by biosurfactant Rufisan produced by Candida lipolytica. J. of Petr. Sci. \& Engin. v. 109, p. 117-122, 2013.

SILVA, R. S.; FARIAS, C. B. B.; RUFINO, R. D.; LUNA, J. M.; L. FILHO, H. J. B.; SANTOS, V. A. ; Sarubbo, Leonie Asfora . Enhancement of biosurfactant production from Pseudomonas cepacia CCT6659 through optimisation of nutritional parameters using response surface methodology. Tenside, Surfactants, Detergents, v. 50, p. 137-142, 2013.

SINGH, A. K.; CAMEOTRA, S. S. Efficiency of lipopeptide biosurfactants in removal of petroleum hydrocarbons and heavy metals from contaminated soil. Environ. Sci. Pollut. Res. Int. v. 20, p. $7367-$ 7376, 2013.

SOUZA SOBRINHO, H. B.; LUNA, J. M.; RUFINO, R. D.; PORTO, A. L. F.; SARUBBO, L. A. Assessment of toxicity of a biosurfactant from Candida sphaerica UCP 0995 cultivated with industrial residues in a bioreactor. Electr. J. of Biotech. v. 16, p. 1-12, 2013.

SOUZA, H. B.; LUNA, J. M.; RUFINO, R. D.; PORTO, A. L. F.; SARUBBO, L. A. Assessment of toxicity of a biosurfactant from Candida sphaerica UCP 0995 cultivated with industrial residues in a bioreactor. Electr. J. of Biotech. v. 16, p. 1-12, 2013.

TIQUIA, S.M.; TAM, N.F.; HODGKISS, I. J. Effects of composting on phytotoxicity of spent pigmanure sawdust litter. Environ. Pollut. v. 93, p. 249-256, 1996. 